\title{
Aglaenita Spinola: descrição de três novas espécies do Brasil com chave para machos (Hemiptera, Cicadellidae, Neocoelidiinae) ${ }^{1}$
}

\author{
Larissa de Bortolli Chiamolera ${ }^{2} \&$ Rodney Ramiro Cavichioli ${ }^{2}$
}

1 Contribuição número 1414 do Departamento de Zoologia, Universidade Federal do Paraná.

${ }^{2}$ Departamento de Zoologia, Universidade Federal do Paraná. Caixa Postal 19020, 81531-980 Curitiba, Paraná, Brasil. Bolsista CNPq. E-mail: larissachiamolera@bol.com.br; cavich@bio.ufpr.br

\begin{abstract}
Aglaenita Spinola: description of three new species from Brazil with a key to males (Hemiptera, Cicadellidae, Neocoelidiinae). Three new species of Aglaenita Spinola, 1850 are described: Aglaenita similis sp. nov., Aglaenita elegans sp. nov. and Aglaenita dubia sp. nov. from Amazonas State, Mato Grosso State and Rio de Janeiro State, Brazil, respectively. Illustrations and a key for the species and new occurrences for $A$. bipunctata Spinola, 1850 are presented. The three new species are similar among them, even so they can be distinguished by the aspect of the male genitalia, mainly by the aedeagus and pygofer.
\end{abstract}

KEY WORDS. Aglaenita, Cicadellidae, Hemiptera, Neocoelidiinae, new species.

Aglaenita foi descrita por Spinola (1850a,b), designando como espécie-tipo: Aglenita [sic] bipunctata Spinola, 1850.

Cavichioli (1999) redescreveu o gênero e solucionou o problema da dupla grafia do nome do gênero: Aglaenita e Aglenita; conforme as normas do C.I.N.Z. permaneceu Aglaenita. Nesse mesmo trabalho, o gênero foi transferido de Idiocerinae, incluído por Metcalf (1966) em Neocoelidiinae.

Estudando os espécimes depositados na "Coleção de Entomologia Pe. Jesus Santiago Moure" do Departamento de Zoologia da Universidade Federal do Paraná (DZUP) e da Coleção do Instituto Nacional de Pesquisas da Amazônia (INPA), foram descobertas três novas espécies: Aglaenita similis sp. nov., Aglaenita elegans sp. nov., Aglaenita dubia sp. nov. e apresenta-se também uma chave para a separação das espécies, com base da genitália dos machos.

As técnicas para exame das genitálias de machos seguem OMAN (1949), com pequenas alterações e a terminologia adotada na descrição das espécies é a de Kramer (1964), exceto para as estruturas da cabeça, a qual segue HamiLton (1981) e MEjDALANi (1998). As medidas são fornecidas em milímetros.

\section{Aglaenita bipunctata Spinola, 1850}

Aglenita [sic] bipunctata Spinola, 1850b: 174.

Novas ocorrências. Brasil, Roraima: Ilha de Maracá, Rio Uraricoera, 1 macho, 21-30/XI/1987, J.A. Rafael e equipe leg., (Armadilha de luz); 1 macho, 22-23/XI/1987, N.O. Aguiar et al. leg., (Luz Mista). Amazonas: BR 174, km 45, 1 macho, 9/IV/ 1982, E.L. Oliveira leg., Coari, Rio Urucu, 1 macho, 07-14/IX/ 1992, Bührnhein leg., para esta localidade são apresentadas duas formas diferentes de pigóforos dos machos (Figs 23 e 24). [INPA]. Espiríto Santo: Linhares, 1 macho, IX/1972, M. Alvarenga leg. [DZUP].

\section{Aglaenita similis sp. nov. Figs 1-9}

Holótipo macho. BrasiL, Amazonas: Coari, Rio Urucu, proximidade IMT-1, 449'33"S/ 6501'49”W, 17-29/IX/1995, P.F. Bührnheim \& N.O. Aguiar leg. [INPA].

Diagnose. Edeago com expansões laterais voltadas para cima no ápice; pigóforo com elevação no terço apical da margem dorsal, sendo a margem irregular, terminando num ápice estreitado pontiagudo, voltado para cima.

Holótipo macho. Medidas: comprimento total 10,80; comprimento mediano da cabeça 0,76 ; distância transocular 1,84; distância interocular 1,00; comprimento mediano do pronoto 1,00; distância transumeral 2,64; largura máxima do escutelo 2,04; comprimento mediano do escutelo 2,12; comprimento das asas anteriores 8,60; largura máxima das asas anteriores 2,68.

Cabeça, em vista dorsal, pronunciada, comprimento mediano aproximadamente $2 / 5$ da largura transocular, margem anterior angulada, com carena na transição entre a coroa e a face, superfície da coroa lisa; ocelos localizados logo abaixo da transição da coroa com a face, na margem anterior da coroa, logo acima dos lóbulos supra-antenais, mais próximos dos olhos do que entre si; lóbulos supra-antenais, em vista dorsal, não protuberantes e, lateralmente carenados e retilíneos com margem posterior arredondada. Fronte, em vista lateral, não 


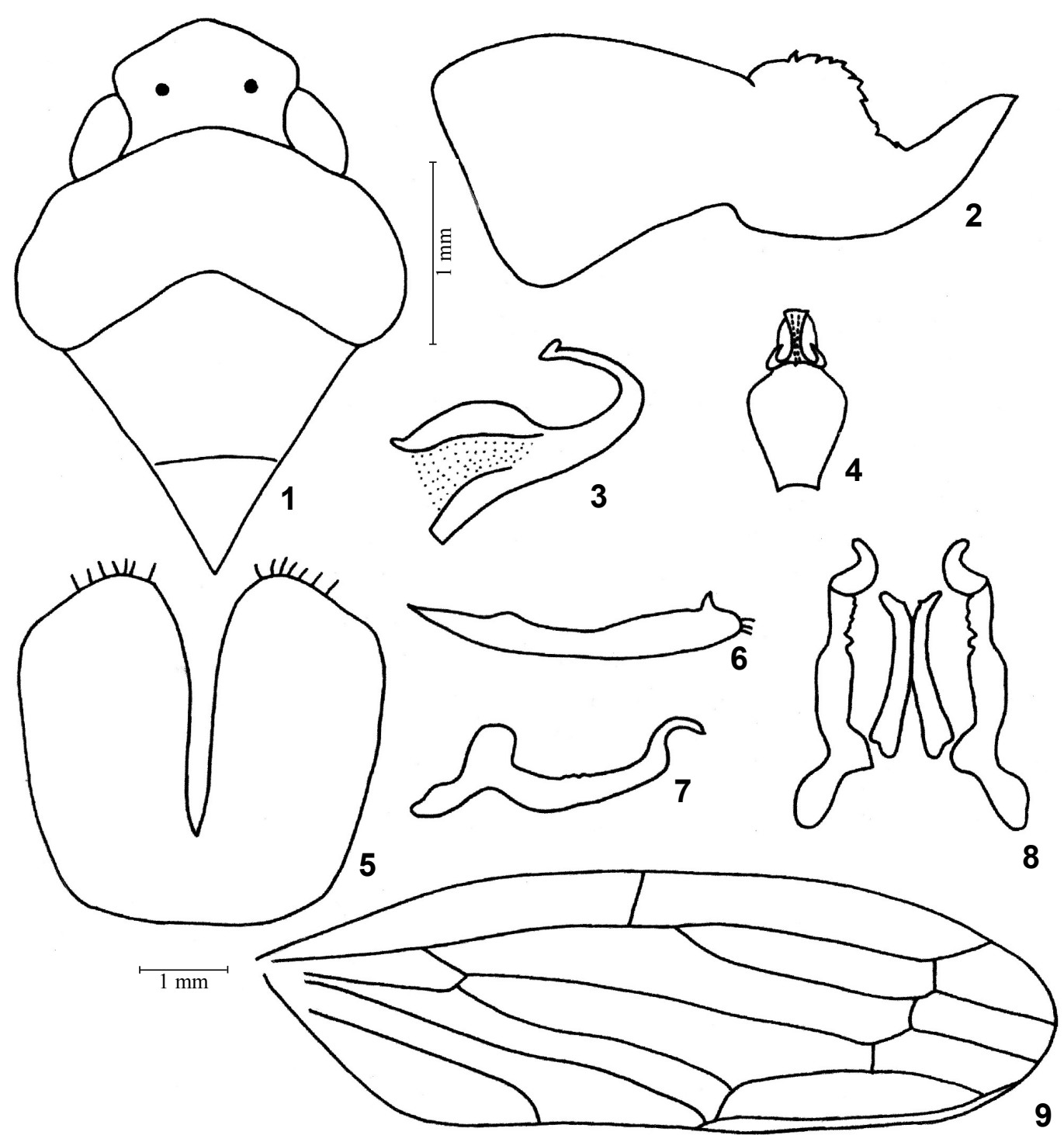

Figuras 1-9 Aglaenita similis sp. nov.: (1) cabeça, pronoto e escutelo, vista dorsal; (2) pigóforo, vista lateral; (3) placa subgenital, vista ventral; (4) edeago, vista lateral; (5) edeago, vista dorsal; (6) placa subgenital, vista lateral; (7) estilos e conetivo, vista dorsal; (8) estilo, vista lateral; (9) asa anterior.

arqueada; superfície pontuada; clípeo retangular, contínuo com a fronte e, em vista lateral, com elevação mediana; sutura epistomal completa.

Pronoto com margem posterior com reentrância mediana; carena dorsopleural completa; superfície enrugada. Asas anteriores pouco mais que três vezes mais longas que largas, venação distinta, com quatro células apicais, base da terceira mais apical que a da segunda; apêndice pequeno estendendose até o começo da segunda célula apical; com três células anteapicais, com a externa fechada.

Genitália masculina. Pigóforo alongado, terminando num ápice pontiagudo voltado para cima, terço apical da mar- gem dorsal com uma elevação e enrugada, margem basal e o terço basal ventral fortemente esclerotinizado. Placas subgenitais curtas, bipartidas por quase todo o seu comprimento e, em vista lateral, com um dente apical; em vista dorsal com reentrâncias esclerotinizadas internas e com algumas microcerdas apicais. Estilos longos, delgados com ápice em "S" voltado para cima e com margem interna irregular. Conetivo em forma de "V" invertido com carena mediana. Edeago, em vista lateral, alargado da base até o meio, sendo a área central membranosa; do meio até o ápice afilado, curvando-se dorsalmente; ápice com expansões laterais viradas para cima.

Fêmea desconhecida. 

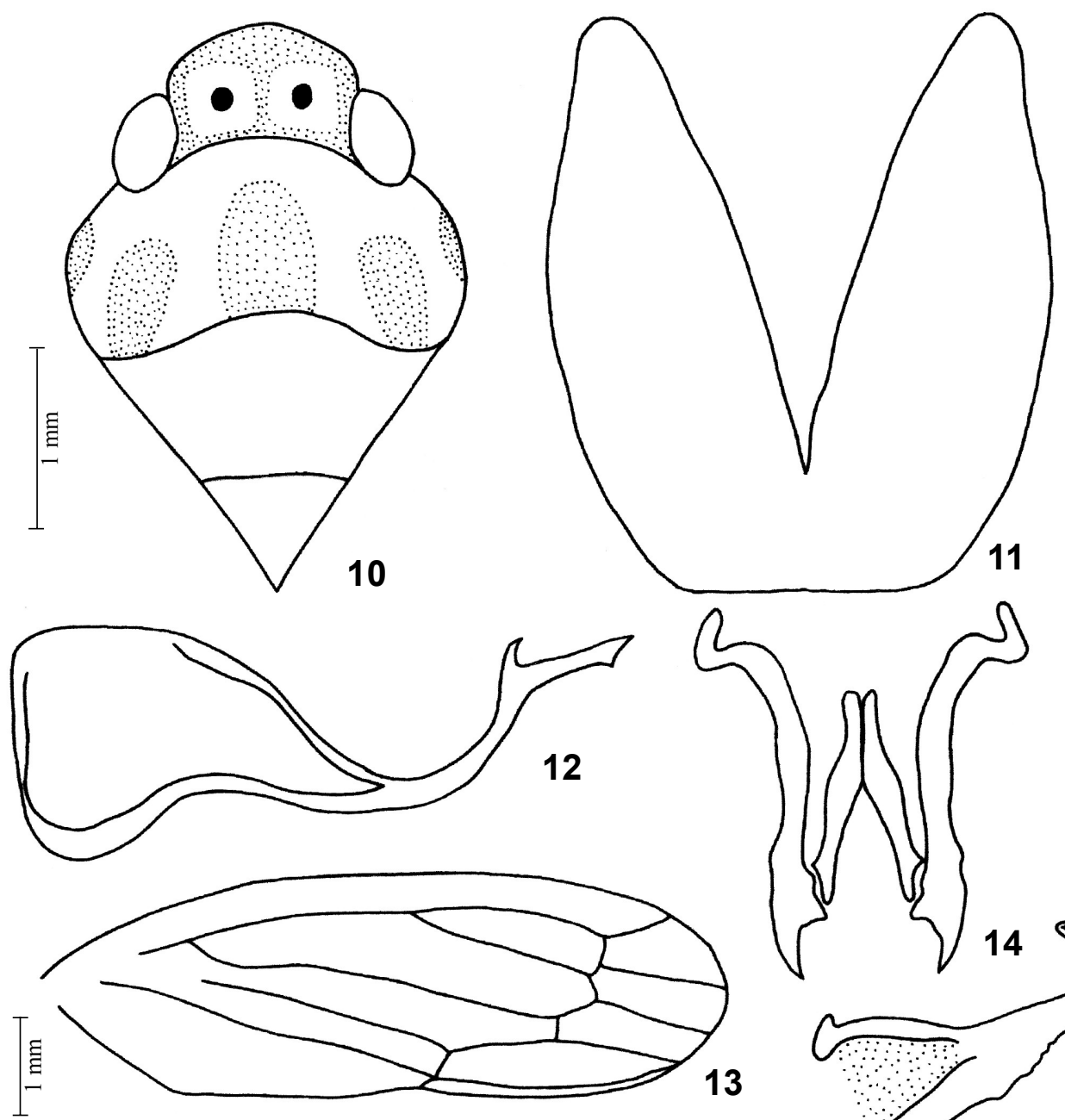

13

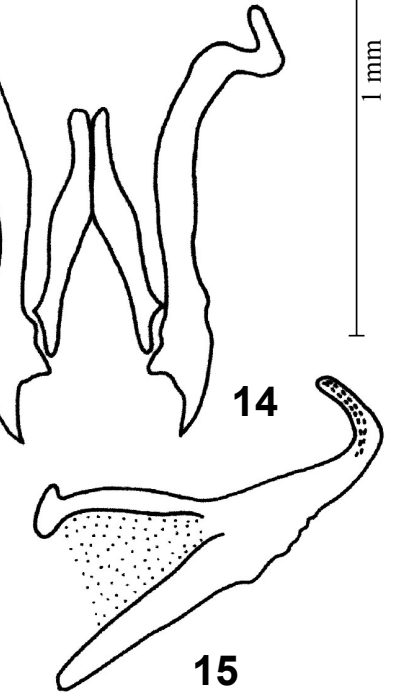

Figura 10-15. Aglaenita elegans sp. nov.: (10) cabeça, pronoto e escutelo, vista dorsal; (11) placa subgenital, vista ventral; (12) pigóforo, vista lateral; (13) edeago, vista lateral; (14) estilos e conetivo, vista dorsal; (15) asa anterior.

Coloração. No geral amarelada, com duas manchas escuras no centro da coroa; asas anteriores hialinas, com veias amarelas.

Comentários. Aglaenita similis sp. nov. é semelhante no aspecto geral com $A$. bipunctata Spinola, 1850, diferindo nos aspectos da genitália do macho, principalmente no ápice do edeago e formato do pigóforo.

Etimologia. O nome da espécie é alusivo a semelhança com Aglaenita bipunctata Spinola, 1850.

\section{Aglaenita elegans sp. nov. Figs $10-15$}

Holótipo macho. BrasiL, Mato Grosso: Sinop, X/1975, M. Alvarenga leg.. [DZUP].

Diagnose. Pigóforo relativamente comprido e afilado do meio até o ápice onde termina num ápice bífido, sendo o ramo terminal maior que o anterior e com margem truncada. Edeago alargado basalmente com margem ventral ligeiramente denteada na região mediana, com ápice curvado anteriormente; Holótipo macho. Medidas: comprimento total 8,80; comprimento mediano da cabeça 0,60 ; distância transocular 1,60; distância interocular 0,88; comprimento mediano do pronoto 0,88; distância transumeral 2,20; largura máxima do escutelo 1,76; comprimento mediano do escutelo 1,44; comprimento das asas anteriores 7,20; largura máxima das asas anteriores 2,32 .

Cabeça, em vista dorsal, pronunciada, comprimento mediano aproximadamente $2 / 5$ da largura transocular, margem anterior ligeiramente angulada. Asas anteriores aproximadamente três vezes mais longas que largas; venação distinta, apêndice pequeno estendendo-se até a metade da segunda

Revista Brasileira de Zoologia 20 (3): 379-383, setembro 2003 


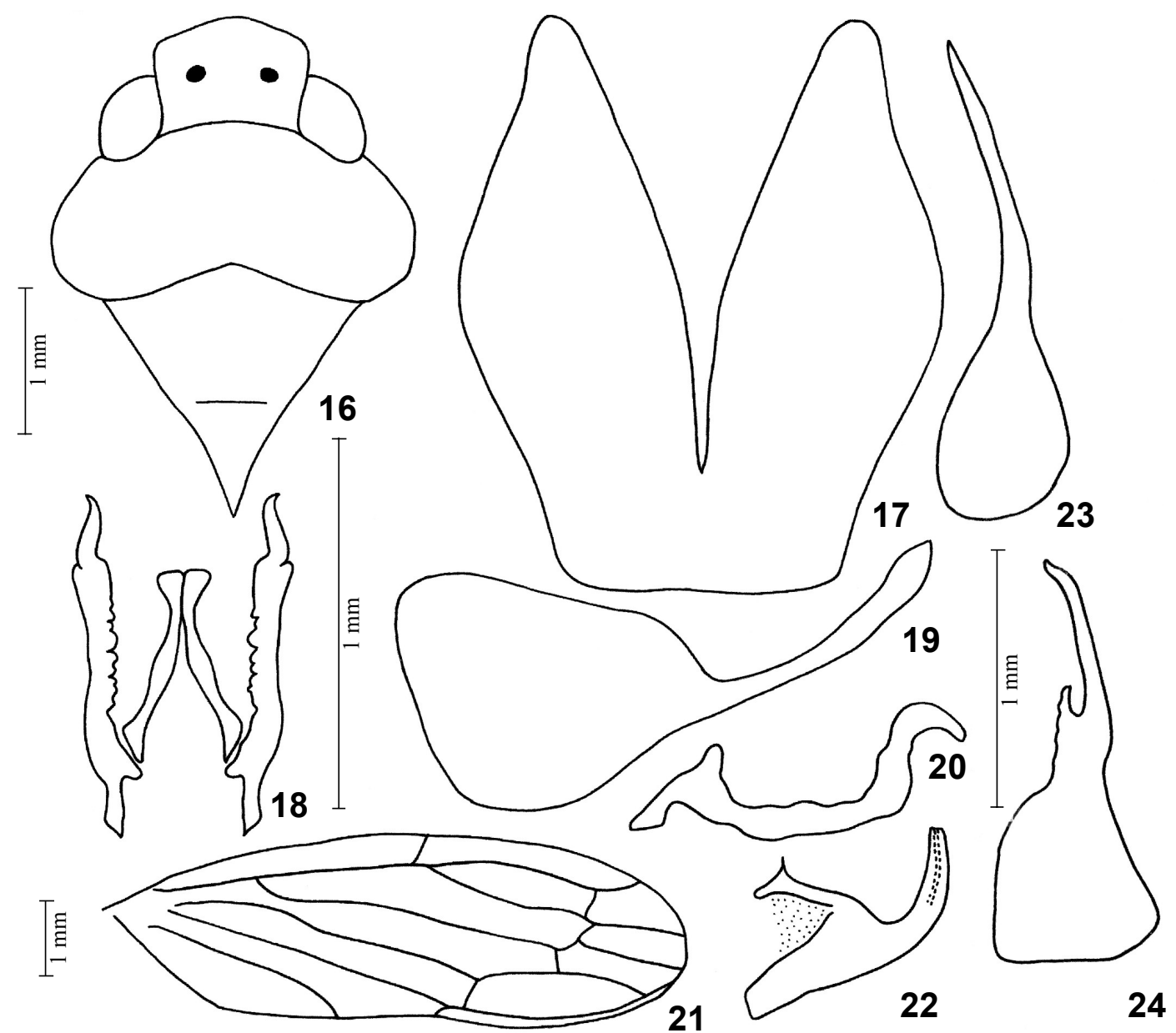

Figuras 16-24. (16-22) Aglaenita dubia sp. nov.: (16) cabeça, pronoto e escutelo, vista dorsal; (17) placa subgenital, vista ventral; (18) pigóforo, vista lateral; (19) estilos e conetivo, vista dorsal; (20) edeago, vista lateral; (21) estilo, vista lateral; (22) asa anterior; (23-24) Aglaenita bipunctata: (23) pigóforo-variante, vista lateral; (24) pigóforo-variante, vista lateral.

célula apical. Demais características semelhantes as de Aglaenita similis sp. nov.

Genitália masculina. Pigóforo alargado basalmente e estreitando-se do meio para o ápice, onde é bífido. Placa subgenital fusionada apenas no terço basal e com uma expansão lateral mediana. Estilos afilados apicalmente, com margem interior irregular. Conetivo em forma de "V" invertido com carena mediana. Edeago sem processos, na metade da margem ventral com leves denteações, terço apical recurvado para cima e com projeção anterior basal.

Fêmea desconhecida.

Coloração. No geral amarelada, com manchas alaranjadas na cabeça, pronoto e base das asas anteriores; com duas máculas escuras no centro da coroa; asas anteriores amarelohialinas, com veias amarelas.

Comentários. Aglaenita elegans sp. nov. é similar no aspecto geral a $A$. similis sp. nov. e $A$. bipunctata diferindo, além da coloração da cabeça, pronoto e escutelo, no formato do pigóforo, e nas denteações na margem ventral do edeago. Etimologia. O nome da espécie é alusivo a sua coloração externa.

\section{Aglaenita dubia sp. nov. Figs $16-22$}

Holótipo macho. Brasil, Rio de Janeiro [Distrito Federal na etiqueta]: Rio de Janeiro, Floresta da Tijuca, VIII/1957, M. Alvarenga leg. [DZUP].

Diagnose. Edeago com margem ventral lisa, sem dentes e sem curvatura apical; pigóforo relativamente comprido e afilado à partir da sua metade, terminando num ápice ligeiramente pontiagudo.

Holótipo macho. Medidas: comprimento total 9,60; comprimento mediano da cabeça 0,64 ; distância transocular 1,68; distância interocular 0,96; comprimento mediano do pronoto 0,88 ; distância transumeral 2,28; largura máxima do 
escutelo 1,80; comprimento mediano do escutelo 1,52; comprimento das asas anteriores 7,80; largura máxima das asas anteriores 2,32 .

Cabeça, em vista dorsal, pronunciada, comprimento mediano aproximadamente $2 / 5$ da largura transocular, margem anterior ligeiramente angulada. Asas anteriores aproximadamente três vezes mais longas que largas; venação distinta, apêndice pequeno estendendo-se até o fim da primeira célula apical. Demais características semelhantes à das duas espécies anteriores.

Genitália masculina. Pigóforo alongado, largo basalmente, com um forte estreitamento da região mediana para o ápice, terminando agudamente. Toda a margem anterior, ventral e parte da dorsal do pigóforo mais esclerotinizada. Placas subgenitais ligeiramente mais compridas que largas e fusionadas apenas no terço basal. Estilos encurvados apicalmente para dentro. Conetivo em forma de "V" invertido com carena mediana. Edeago sem processos, com ligeiro encurvamento na sua metade, subindo retilineamente até o ápice retilíneo, margem ventral lisa, sem denteações, terço apical recurvado para cima e com projeção anterior basal.

Fêmea desconhecida.

Coloração. No geral amarelada, com duas manchas de cor ferrugem no centro da coroa; asas anteriores amarelohialinas com veias amarelas.

Comentários. Aglaenita dubia sp. nov. é semelhante externamente às espécies de Aglaenita, sendo que o formato do edeago é semelhante ao de $A$. similis sp. nov., onde a margem ventral é lisa, porém não apresenta as expansões no seu ápice. Etimologia. O nome é alusivo à dúvida que os espécimes apresentam quando comparadas com as espécies do gênero.

\section{Chave para as espécies de Aglaenita Spinola, 1850}

1. Edeago com margem ventral com denteações .................... 2

1 '. Edeago com margem ventral lisa

2.2. Ápice do edeago retilíneo; pigóforo estreitado à partir da sua metade Aglaenita dubia

2 '. Ápice do edeago com expansões laterais; pigóforo alargado com elevação enrugada no terço da margem dorsal .......... Aglaenita similis

3.3. Edeago com dentes nítidos na margem ventral; coloração amarelada somente com duas máculas pretas no centro da coroa . Aglaenita bipunctata

3'. Edeago com dentes não tão definidos como no acima; coloração além das duas máculas pretas no centro da coroa, também manchas alaranjadas na cabeça, pronoto e base das asas anteriores ................................. Aglaenita elegans

\section{AGRADECIMENTOS}

Agradecemos ao Conselho Nacional de Desenvolvimento Científico e Tecnológico (CNPq), pelo auxílio concedido referente ao Proc. número 475565/01-0, bolsa de mestrado e Produtividade em Pesquisa.

\section{REFERÊNCIAS BIBLIOGRÁFICAS}

CAVICHIOLI, R.R. 1999. Aglaenita Spinola and A. bipunctata Spinola (Hemiptera, Auchenorrhyncha, Cicadellidae): redescription of both taxa and taxonomic notes. Revista Brasileira de Zoologia, Curitiba, 16 (1): 189-192.

HamiLton, K.G.A. 1981. Morphology and evolution of the rhynchotan head (Insecta: Hemiptera, Homoptera). Canadian Entomologist, Ottawa, 113 (11): 953-974.

KRAMER, J.P. 1964. A generic revision of the leafhopper subfamily Neocoelidiinae. (Homoptera: Cicadellidae). Proceedings of the National Museum, Washington, D.C., 115 (3484): 259287.

Mejdalani, G.L.F. 1998. Morfologia externa dos Cicadellinae (Homoptera: Cicadellidae): Comparação entre Versigonalia ruficauda (Walker) (Cicadellini) e Tretogonia cribrata (Melichar) (Proconiini), com notas sobre outras espécies e análise da terminologia. Revista Brasileira de Zoologia, Curitiba, 15 (2): 451-544.

Metcalf, Z.P. 1966. General catalogue of the Homoptera. Fascicle VI. Cicadelloidea. Part 16. Idiocerinae. Washington, U.S. Department of Agriculture Research Service, 237p.

Oman, P.W. 1949. The Nearctic leafhoppers (Homoptera: Cicadellidae). A generic classification and check list. Memoirs of The Entomological Society of Washington, D.C., 3: 1-253.

SpINOLA, M. 1850a. Tavola Sinopttica dei generi spettanti alla classe degli insetti artroidignati, Hemiptera, Linn. Latr., Rhyngota, Fab, - Rhynchota, Burm. Memorie di Matemática e Física della Sociedade Italiana delle Scienze, Modena, 25 (1): 43-100.

. 1850b. Di algunci generi d'insetti artroidignati nuovamente proposti dal socio attuale Signor Marchese Massimiliano Spinola nella sua tavola sinottica di questo ordine che precede la presente memoria. Memorie di Matemática e Física della Sociedade Italiana delle Scienze, Modena, 25 (1): 101-178.

Recebido em 09.I.2003; aceito em 13.V.2003.

Revista Brasileira de Zoologia 20 (3): 379-383, setembro 2003 